\title{
HISTÓRIA E IMAGEM, METAMORFOSES ${ }^{1}$
}

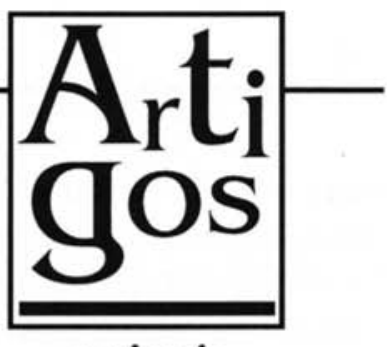

nacionais

\section{As Artes Plásticas, a Fotografia, o Cinema e a Televisão são formas de representação da imagem que o homem faz de si mesmo}

Antes de começar a discutir o problema da História e da Imagem, gostaria de esclarecer porque, sempre que apresento minhas reflexões, atribuo tanta importância ao mundo contemporâneo. Como historiador, venho de uma formação da Escola dos Anais e, embora tenha sido aluno de Fernand Braudel $^{2}$, hoje me volto cada vez mais para um dos fundadores dessa Escola, Lucien Febvre. É de Lucien Febvre uma frase que jamais esqueço: "Para fazer História, virem as costas ao passado e vivam o presente".

Sempre parto dos problemas da atualidade para pensar na História, no seu desfiar, no seu processo. Por que História e por que Imagem, por que metamorfoses? Quanto mais estudo a História, quanto mais percorro esse processo do homem, mais tenho certeza de que há um substrato humano que não se modifica, que é uma permanência. Amor, ódio, vingança, nobreza, fidelidade etc. são coisas que ressaltam a origem. Ou seja, é um substrato que não se modifica ao longo da História. Mas o homem tem um ardil: quando a sua imagem se desgasta, ele a recompõe. Os períodos históricos têm mostrado que o homem vai refazendo sua própria maneira de olhar-se. Quando sua imagem se desgasta, temos um surto de novas idéias, um surto de novas posições, que refazem a imagem que ele faz de si próprio.
Há na história momentos em que ocorre uma espécie de libertação, de frouxidão dos costumes, que levam o homem a percorrer e a montar o que chamo de períodos libertinos. É como um pêndulo. Há os períodos libertinos e, ao mesmo tempo, a reação a eles, provocando o que denomino de períodos puritanos. Essas afirmações são conclusões de uma pesquisa que comecei a desenvolver em 1994 - História, Imagem e Metamorfose.

A primeira imagem que o homem faz de si próprio é aquela muito conhecida, do homem atacado por um bisonte ferido. Está na Gruta de Lascaux e é a primeira vez que o homem desenha a si próprio. É uma cena fantástica, na qual aparece um bisonte com o ventre rasgado, os intestinos já saindo e, pelo processo da Imagem, vê-se que tinha acabado de ferir ou matar um homem.

Apelando para as influências freudianas, vale lembrar que, já nessas primeiras imagens, o homem primitivo deixa bem

\section{O AUTOR}

\section{Virgílio B. Noya Pinto}

Professor Doutor Titular do Departamento de Comunicações e Artes da ECA-USP. Autor de Comunicação e cultura brasileira, entre outros. 
claro o que é homem, o que é mulher. Quer dizer, quando os homens são representados, há sempre uma preocupação com a genitália masculina, da mesma maneira quanto à mulher: ela é representada na sua forma volumosa, como por exemplo a Vênus de Willendorf, a Vênus de Laussel, nas quais a idéia de gênesis, de fecundidade fica bem clara. O que chama a atenção nessas primeiras imagens que o homem faz de si próprio é a distinção homem/mulher.

\section{A IMAGEM DO HOMEM NO PERÍODO CLÁSSICO}

Avançando na História, verificamos que, quando se repassa o mundo egípcio, manifesta-se o problema da postura das imagens: o perfil, o frontal, como a História da Arte já assinalou suficientemente. É um milênio (2.580-1580 a.C.) quase imutável para a História do Egito, só modificado quando ocorre a transgressão ao processo da história egípcia, provocada pela $18^{\text {a }}$ dinastia (1580 a.C.). Sem dúvida nenhuma, o isolamento geográfico do Egito provocou essa permanência de milênio. Observa-se que essa visão com relação ao homem se desfaz no momento da ruptura do isolamento do Egito. A $18^{\mathrm{a}}$. dinastia é aquela que reconquista o Egito da invasão dos hicsos. Há a reconquista e depois a expansão. É esse contato com o mundo que propicia ao Egito criar uma arte com uma visão diferenciada, mas naturalmente envolvida em problemas religiosos. É um momento extremamente belo em termos de produção artística. O monarca é Amenófis IV, marido da Nefertite. Toda a beleza retratada na imagem de Nefertite se deve à implosão da tradição egípcia aliada a um processo de inovação que foi relativamente curto. $\mathrm{O}$ peso da tradição egípcia termina se reimpondo, rompendo-se novamente só a partir do momento em que o Egito é absorvido pelo mundo helenístico.

Quando se passa para o mundo grego, o que me parece essencial é a idéia de cidadania, pois, até então, as sociedades conservavam um pouco daquela tradição da pirâmide dos primatas, núcleo, enfim, de toda a formação da sociedade.

Ao tratar de pirâmide primata, refirome às recentes pesquisas feitas com os primatas, sobretudo o gorila e o chimpanzé, em que se verifica que a organização desses animais se estrutura com um macho dominante no ápice da pirâmide, em seguida os machos que estão sempre em luta para se tornar dominante e, finalmente, as fêmeas e os adolescentes. Esse esquema social, que se encontra em quase todos os primatas, certamente foi o ponto de partida da organização da sociedade humana. No mundo grego isso se rompe. Ainda na sociedade egípcia se encontra essa pirâmide social hierarquizada; na Mesopotâmia a mesma coisa, na China, enfim, em todas as culturas anteriores ao mundo grego. No mundo grego isso se rompe. Rompe-se no processo de gestação da cidadania, ou seja, há uma reconstrução do homem, uma primeira reformulação do homem em que a cidadania, a idéia da pólis vai criar uma nova imagem e essa nova imagem é a do homem ideal.

Sabemos que os gregos não representavam o ser humano tal como ele era, mas de forma idealizada. A realidade transfigurada. De tal maneira que essa arte, essa visão do homem, pela primeira vez vai ter o seu código de proporções com o Doríforo de Policleto, que faz o primeiro estudo da proporção humana, depois com Praxíteles, Escopas e Lisipo, principalmente. Como se vê, estou recorrendo à História da Arte na 


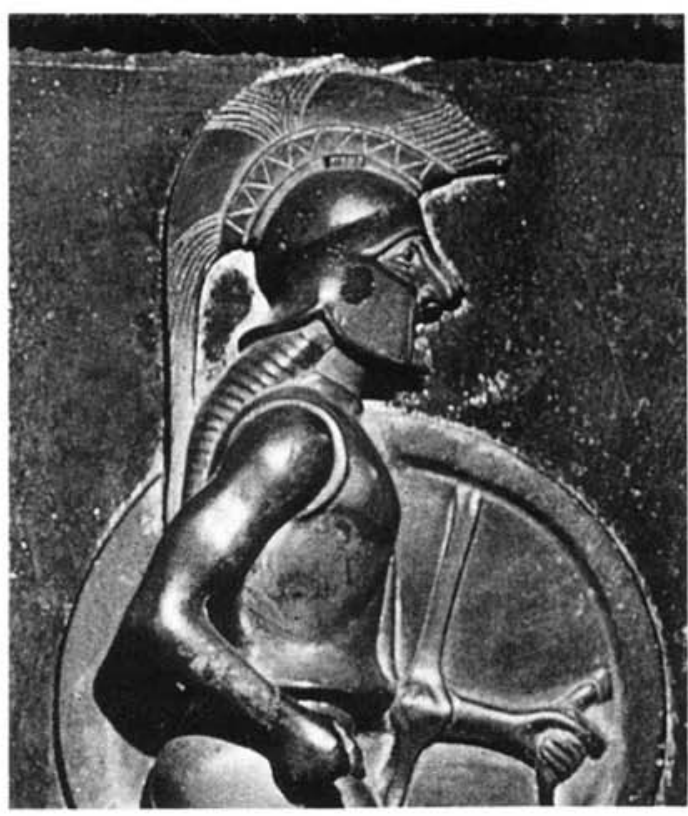

Péricles é a imagem da idade áurea de Atenas, a primeira democracia da História.

medida em que é ela que fornece a documentação mais precisa. Mas a arte grega, além dessa visão idealizada da realidade, traz também, pela primeira vez, as emoções humanas, principalmente nas estelas funerárias, lápides nas quais se faziam inscrições artísticas, onde constavam o nome do morto e as referências de relevo. As estelas funerárias gregas expressam sentimentos, sobretudo de dor e de saudades. Os grandes pintores e escultores do mundo grego, com sua arte idealizada, não revelavam esse sentimento. Mas existe uma arte menor, popular, na qual todo esse sentimento e essa dor da perda são expressos e, pela primeira vez, pode-se perceber, através da história da imagem, exatamente essa tentativa de captar o homem num momento de dor. É pertinente estabelecer uma relação entre as estelas funerárias e as tragédias no teatro como, por exemplo, através da associação da imagem gravada numa estela, na qual se vê uma avó sentada com o neto no colo, com o olhar expressando a dor de abandoná-lo, com a imagem da rainha Hécuba, quando ela se despede do neto, Astianax, na peça As troianas, de Eurípedes. Considero que essa imagem da estela funerária expressa, em termos da escultura, aquilo que o teatro vai expressar com as grandes personagens, como a extraordinária Mater Dolorosa pagã que é a rainha Hécuba.

Ao entrarmos no mundo romano, o conceito de cidadania se modifica, modificando-se, na mesma proporção, toda a postura. Como se sabe, há a influência grega, helenística.

O mundo romano vai gerar uma idéia nova, que é o conceito do homem universal. A partir do Edito de Caracala, todos os homens livres do Império são considerados cidadãos romanos. Graças à amplitude desse gesto, instala-se o conceito da universalidade da cultura romana, do Direito romano, do Estado romano, a primeira Aldeia Global, enfim.

A modernidade de Roma é extraordinária e podemos percebê-la a partir dos problemas que nos chegaram. Ela é a primeira grande metrópole e todos os problemas urbanos contemporâneos nela também podem ser encontrados. Pode-se detectar o problema de trânsito, o problema de abastecimento, até mesmo a periculosidade de uma cidade gigantesca. $\mathrm{O}$ apogeu de Roma, como centro urbano, como centro de um Estado universalizado, pode ser percebido através da obra literária, Satiricon, de Petrônio. Essa obra nos dá exatamente a imagem da opulência de Roma, para a qual todo o Império trabalha.

A imagem do homem se completa um pouco mais em Roma. Grande parte dos críticos de Arte nos falam da pintura romana como uma cópia do mundo grego. Porém, 
na medida em que se vê a pintura grega, seja através dos afrescos que hoje estão sendo descobertos nos túmulos, seja através da pintura na cerâmica, percebe-se uma diferença muito grande em relação à pintura romana, na qual o volume, a sombra e a perspectiva se apresentam como um aspecto novo. Ou seja, se temos no mundo grego o homem captando os sentimentos, temos no mundo romano o homem se destacando através do espaço. Aqui, a criação de uma perspectiva revela a visão que o homem tem de si próprio, adquirindo um determinado volume. O mundo romano nos dá uma idéia diferenciada daquela do mundo grego, com uma realidade não idealizada. A procura do realismo em Roma é percebida principalmente através dos retratos, mesmo dos retratos dos imperadores, nos quais, comparados às biografias respectivas, pode-se sentir o quanto a imagem do Imperador se coaduna com a sua postura. Por exemplo, quando se vêem as imagens de Diocleciano, no apogeu do Absolutismo em Roma, sente-se inclusive toda a influência do despotismo oriental naquele momento.

Paralelo a tudo isso vai emergir o homem cristão. Cristo pregou, foi crucificado e deixou para os seus seguidores a implantação de uma Igreja. Essa implantação foi realizada em parte por São Paulo, através das Epístolas, com respostas às dúvidas que vão surgindo dentro do mundo cristão na medida em que o próprio cristianismo se expande. A primeira grande questão que permite perceber a ruptura do cristianismo com o judaísmo ocorre no Concílio de Jerusalém, em que se coloca o problema da circuncisão. $\mathrm{O}$ homem judaico é um homem circundado. Ora, e os novos cristãos? Precisavam ser circundados também? Essa dúvida é resolvida no Concílio de Jerusalém, graças em parte a São Paulo, que faz a defesa da não necessidade da circuncisão aos gentios, como eram chamados naquele momento os não judeus. As Epístolas nos dão a idéia da construção desse novo homem. Nesta construção, é dado destaque para a hierarquização da sociedade. O homem está no topo dessa hierarquia e a ele cabe respeitar a Deus e à mulher cabe respeitá-lo. Não é à-toa que a Igreja Católica pediu desculpas à mulher por suportar esse peso, que em parte se deve a São Paulo, e sobretudo ao culto da castidade.

Santo Agostinho conclui a imagem do homem cristão na Cidade de Deus, quando coloca o problema da obediência. A obediência é alguma coisa que completa a hierarquia que a própria Igreja vai construindo.

A obediência vai ser extremamente aplicada na cidade medieval. Santo Agostinho constrói a cidade ideal, cidade em que parece não haver homens, na medida em que a castidade e a hierarquia prevalecem, formando uma sociedade de anjos. Mas, os anjos vivem nas nuvens, o homem vive na terra; os anjos não têm sexo, o homem tem; os anjos não sentem fome, os homens sentem.

Essa imagem se rompe quando uma figura da cristandade, São Francisco, começa a recolocar o homem dentro da natureza. Quando se lê no Cântico das Criaturas a apologia à água, ao Sol, às estrelas etc. começa a se transformar a imagem do anjo que Santo Agostinho pretendeu. A recolocação do homem na natureza vai implicar a recolocação do homem na perspectiva racional, geométrica, sobretudo na pintura de Paollo Ucello, de Giotto e, finalmente, a retomada do modelo greco-romano a partir do Renascimento, com Botticelli nas suas telas admiráveis como Flora, Vênus e 
Marte, nas quais há um efetivo retorno à sensualidade, uma condenação da castidade como pretendeu o cristianismo. Com Boccaccio isso realmente vai por água abaixo, na medida em que, no Decameron, ele expõe não só a decadência do homem hipocritamente cristão, mas também uma nova ordem moral emergente com a burguesia.

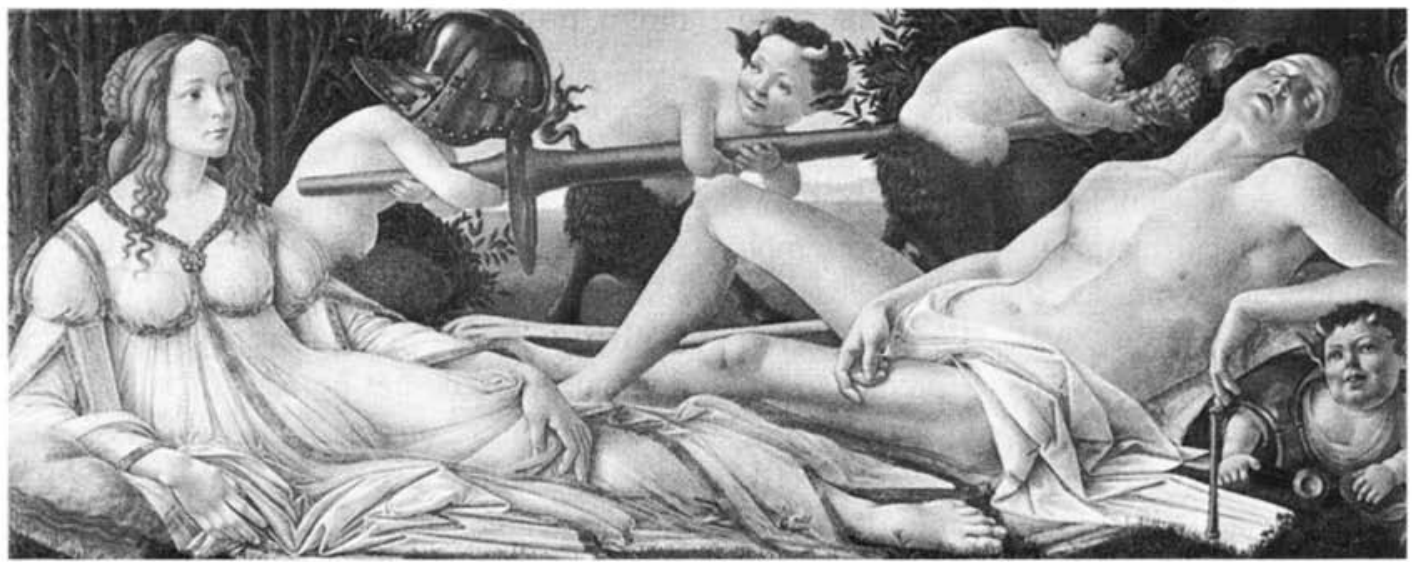

Vênus e Marte $(69$ x $173.5 \mathrm{~cm})$. Sandro Botticelli (séc. XV)

Há, num dos contos do Decameron, uma jovem que tem um namorado. Eles querem se encontrar e ela começa a atormentar o pai e a mãe dizendo que estava muito quente, que estava fazendo calor, que ela precisava dormir na varanda. De tanto insistir, ela consegue seu intento. Era uma combinação dos dois de que ele iria subir até à varanda para passarem uma noite juntos. No dia seguinte, o pai descobre os dois na varanda, nus, e chama a mulher. Aí se vê a transformação dessa visão do homem. Quando se pensa na Idade Média e, por exemplo, na saga germânica, sobretudo dos Nibelungos, em que a honra se lava com sangue - e essa é a grande fusão do germanismo com o cristianismo - Boccaccio, vai mostrar que não se lava mais com sangue. $\mathrm{O}$ tradicional seria que o pai matasse o jovem pela desonra trazida à casa. Entretanto, ele raciocina e pondera com a mulher: a família do rapaz é muito rica. É mais rica do que a nossa. Portanto, é melhor fazer com que eles se casem. E a honra, em vez de ser lavada com sangue, foi pacificada com o dinheiro da junção das duas famílias.
Enfim, isso mostra a nova imagem do homem renascentista. Ela é moldada pelas pesquisas de um Leonardo da Vinci e pelo Cristo hercúleo de Miguel Ângelo na Capela Sixtina, ao lado de suas fraquezas, que estão expostas pelo Elogio da loucura de Erasmo de Roterdã.

No Elogio da loucura, percebe-se com clareza o que eu afirmo no início. Há um substrato humano que persiste, que é permanência, e a loucura nos dá esse quadro de tudo o que o homem suporta, tudo o que o homem modifica, a partir de seus instintos, de todas as suas necessidades psicológicas e físicas, inclusive. Porém, esse homem se atormenta com os textos e as opções religiosas, as quais terminam com a ruptura da cristandade em católicos e protestantes. Não é uma recriação do homem, mas sim uma divisão do homem, em que se percebe uma necessidade muito grande de reelaboração, sobretudo da educação. É um dos grandes momentos em que a educação é vista como uma forma de conquista e de atrelamento a determinadas idéias. Por exemplo, quando Lutero diz que para se atingir a salvação é 
preciso ler a Bíblia, ele está instituindo a necessidade de alfabetização. Para contrabalançar, no Concílio do Vaticano, os jesuítas criam o Catecismo, a cartilha dos católicos. Há, a partir desse momento, uma visão nova da educação.

Mas esse homem da Renascença é um homem que vai desaparecer no final do século XVI, com a intolerância que leva Giordano Bruno ao martírio. Ao mesmo tempo Shakespeare, com as suas três peças do começo do Século XVII, Hamlet, O Rei Lear e Macbeth, mostra o prenúncio do autoritarismo, através do Absolutismo que vai se desenvolver nos séculos XVII e XVIII.

O século XVII é um século de intolerância, um século extrema e hipocritamente puritano, apesar do luxo da realeza e da burguesia. Veja-se, por exemplo, a obra de Frans Hals, que é sobretudo o retratista da burguesia holandesa rica, nesse momento. São retratos nos quais quase todos os personagens estão sorridentes, ou tocando instrumentos, gozando, enfim, de uma vida de luxo e de prazer.

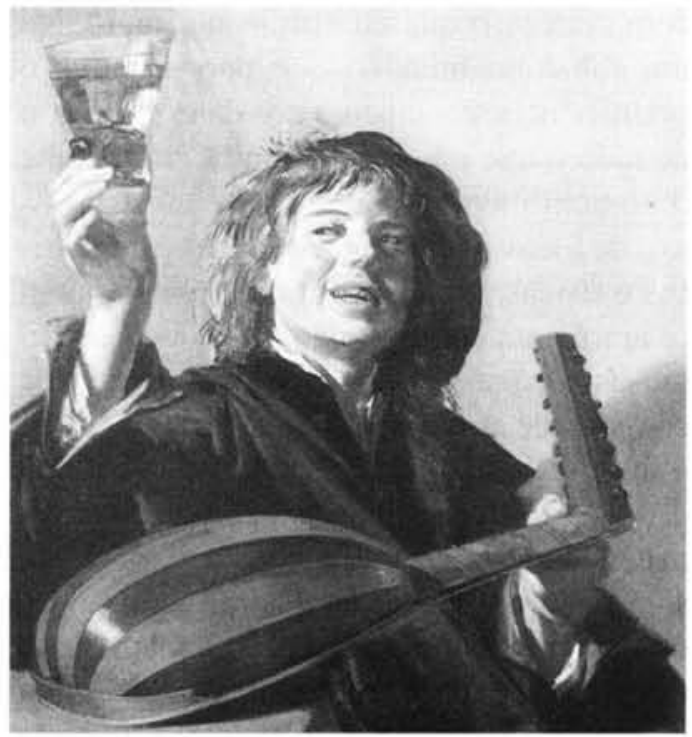

The Lute Player (Pregador Luterano), de Frans Hals, séc. XVII
Por outro lado nós temos também, e isso é importante, a partir do século XVII, uma série de pintores que vão trazer para as suas telas não só a fisionomia do povo, como o próprio sofrimento do povo. Quer dizer, ao mesmo tempo em que temos artistas como Velasquez, Rubens, Frans Hals, que estão retratando a sociedade de luxo da nobreza e da burguesia, temos a miséria retratada por Le Nain, por La Tour, por Murilo e pelo próprio Velasquez. O século XVII assiste, na pintura, à inclusão de um homem novo, de um homem miserável, de feições rudes e sofridas.

O século XVIII é um século de corrupção praticamente em toda a Europa, representada sobretudo pela imagem de Luís XV na França. Corrupção que vai desde a venda de empregos, tramóias etc., até o escândalo do Parc au Cerf, pavilhão do Castelo de Versalles, onde Luís XV mantém encontros com suas amantes, uma espécie de harém que cai na boca do povo.

Uma das coisas mais fascinantes desse século é a imprensa. Ela gera uma imensa produção de folhetins, principalmente sobre a libertinagem da Corte. Madame du Barry, amante de Luís XV, é um dos alvos desta imprensa erótica do século XVIII. Ao lado dos folhetins há uma literatura erótica que nos espanta pela presença de Mirabeau, o velho Mirabeau da Revolução Francesa. Mirabeau, Laclos e Sade compõem a trilogia dos clássicos da literatura popular, em termos de erotismo, e que correspondem à pintura extremamente sensual desse momento. Quando vemos um Fragonard, um Watteau, um Boucher, um Hogarth, podemos sentir o quanto a pintura está ajudando a criar esse homem sensual que é o homem do século XVIII.

Ao passarmos para o processo seguinte, o da Revolução Francesa, uma coisa 
chama a atenção. Por exemplo, o pintor Louis David retrata com traços extremamente rápidos os que estão seguindo para a guilhotina. São extraordinários os croquis da rainha Maria Antonieta e de Danton a caminho do cadafalso.

Ao mesmo tempo há, em todo esse período, uma efervescência entre os desenhistas, os litógrafos e os águas-fortistas, no sentido de captar o momento. Por exemplo, as assembléias tumultuadas da Revolução Francesa são rapidamente rascunhadas como uma espécie de registro do instante.

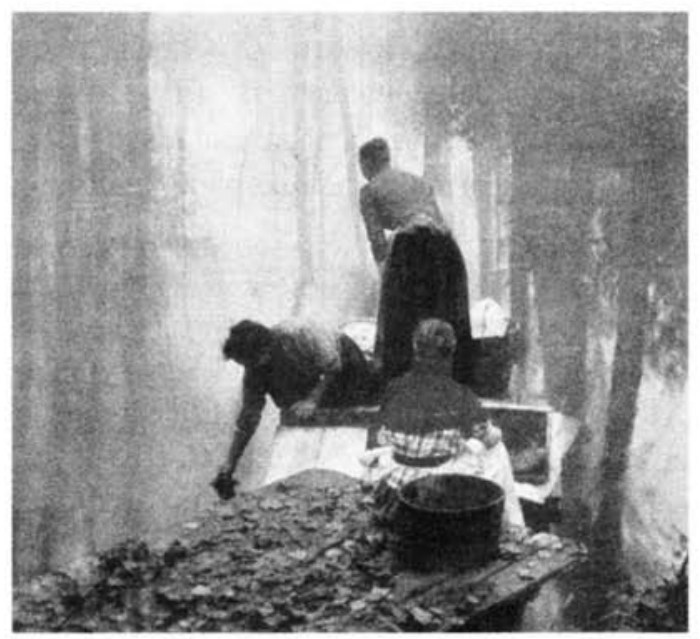

As Lavadeiras. Foto de C.Puyo (1857-1933). A técnica da fotografia aproxima-se das Artes Plásticas.

Há uma evidente preocupação com o registro do tempo que se vive. Isso $\mathrm{me}$ faz pensar que a sociedade está sempre buscando algo capaz de registrar o seu processo histórico.

A fotografia vai nascer logo em seguida. A partir do momento em que o uso da fotografia se propaga, tem-se uma outra fonte para a História da Imagem. O sucesso da fotografia no século XIX é extraordinário. Por um lado, é o retrato, tão cobiçado pela classe média e pela burguesia, que se populariza. Por outro, o uso da fotografia começa a ser fascinante na medida em que esse uso dilata o mundo.

Calcule-se, por exemplo, o europeu no século XIX ao ver uma fotografia das Pirâmides do Egito: é o nascimento do Cartão Postal. Só que o Cartão Postal está trazendo uma nova dimensão para o homem. A partir do momento em que, na Europa, pode-se ver uma fotografia de mulheres algerianas, anteriormente retratadas por Delacroix, por Ingres etc. e também a fotografia de recintos e de prédios, há um alargamento da visão do europeu.

Além do mais, há a influência que a fotografia começa a ter nas Artes Plásticas. Em primeiro lugar como colaboradora. Sabemos que várias telas foram pintadas a partir de retratos de modelos, nus, que aparecem na obra, por exemplo, de Courbet.

O século XIX - e não estou colocando aqui a emergência das novas classes, como a burguesia industrial e o proletariado - é o momento de toda a transformação tecnológica que se estenderá até o século XX. O século XIX é o século matriz e, o que é muito importante, começamos a identificar os momentos de ruptura que estão acontecendo nas Artes Plásticas. Considero o primeiro grupo de ruptura formado por Cèzane, Gauguin e Van Gogh. Depois dele vem um segundo grupo de ruptura, que é mais violento, composto por Klimpt, Tolouse-Lautrec, Matisse, Ensor e Münch. São eles que rompem com aquilo que começo a chamar a implosão da figura humana nas Artes Plásticas. Na medida em que nas Artes Plásticas se encaminha para a implosão da figura humana, vamos ver a fotografia tentando se aproximar das artes. Essa característica pode ser observada no movimento Pictorialista, que acontece no final do século XIX, em que um conjunto de artistas, reunidos em Viena, na primeira grande mos- 
tra de fotografia, afirmam que a fotografia é uma arte.

$\mathrm{Na}$ condição de arte vemos, depois dessa primeira exposição, a aproximação da fotografia com o Impressionismo. Quando se fala no movimento Pictorialista, fala-se justamente da fotografia vinculada ao Impressionismo. E o Impressionismo é, sem dúvida nenhuma, o último dos grandes movimentos em que se preserva, ainda, a imagem do homem. Há uma belíssima Vênus de Renoir que é muito semelhante à Vênus de Knido, estátua grega, praticamente uma das últimas imagens clássicas do homem nas Artes Plásticas.

\section{A IMPLOSÃO DA IMAGEM DO HOMEM NAS ARTES PLÁSTICAS}

A partir desse momento, as Artes Plásticas passam a mostrar essa implosão, essa desestruturação da figura humana. Isso pode ser verificado com Kandinski, Vlamink, Picasso, Braque, Rouault, Dufy, Magritti, Ernst, Klee, Man Ray, entre outros. Pode-se tomar as obras desses pintores, em vários momentos diferentes, e montar uma série, como se montássemos uma espécie de filme. Quase que ano a ano, pode-se perceber como o homem vai sendo desintegrado pela pintura. $\mathrm{O}$ artista já não tem mais nenhum interesse por nada que seja figurativo, até chegarmos à arte de Pollock, que é o estilhaçamento completo do figurativismo. Para mim, que estou à procura da imagem, é muito sintomático isso. A partir desse momento as Artes Plásticas já não interessam mais em termos de como a imagem se transforma. Temos, porém, a fotografia e, a partir de experimentos posteriores, chegamos ao cinema.
Observe-se que enquanto as Artes Plásticas caminham para essa desestruturação da figura, a fotografia e o cinema buscam cada vez mais a nitidez na reprodução da imagem. Essa imagem pode ser distorcida pelo diretor, no espaço da arte cinematográfica, mas há uma tecnologia que se volta para a captação da imagem no seu realismo maior, na sua perfeição maior. Por outro lado, temos uma mudança com relação ao posicionamento da fotografia, sobretudo com o revolucionário fotógrafo Cartier Bresson. A fotografia na busca, sobretudo, do cotidiano. Não a fotografia de pose, mas a captação do cotidiano. É também a partir do século XX que se pode ir sentindo, pela evolução da fotografia, a presença do cinema, da propaganda e da televisão como campos onde se pode analisar a imagem dos nossos dias.

Há também a seguinte questão: nesse pêndulo da História entre libertino e puritano, como se coloca o século XX? O século XIX é extremamente puritano. Ele é a reação ao século XVIII. Se o século XVIII foi um século libertino, o século XIX é um século de oposição. A partir do século XX e sobretudo a partir da década de 50 - porque considero que até a década de 50, até o momento das duas Guerras, essa parte do século XX ainda pertence ao século XIX - começa realmente nova revolução com o Movimento Beat.

O Movimento Beat é a ruptura com toda a representação do passado de ligação entre o século XIX e o século XX. Há uma arte, tanto na Europa quanto nos EUA, que reflete um universo tenso e desordenado. Pierre Soulage, Baumaisser, Giacometti, Bernard Buffet, Francis Bacon, Jack Levine são expressões, nas Artes Plásticas, dessa desestruturação. Mas é a literatura Beat que marca realmente essa ruptura. William Burroughs publicou, em 1950, suas experiências com drogas e sexo, provocando uma enorme 


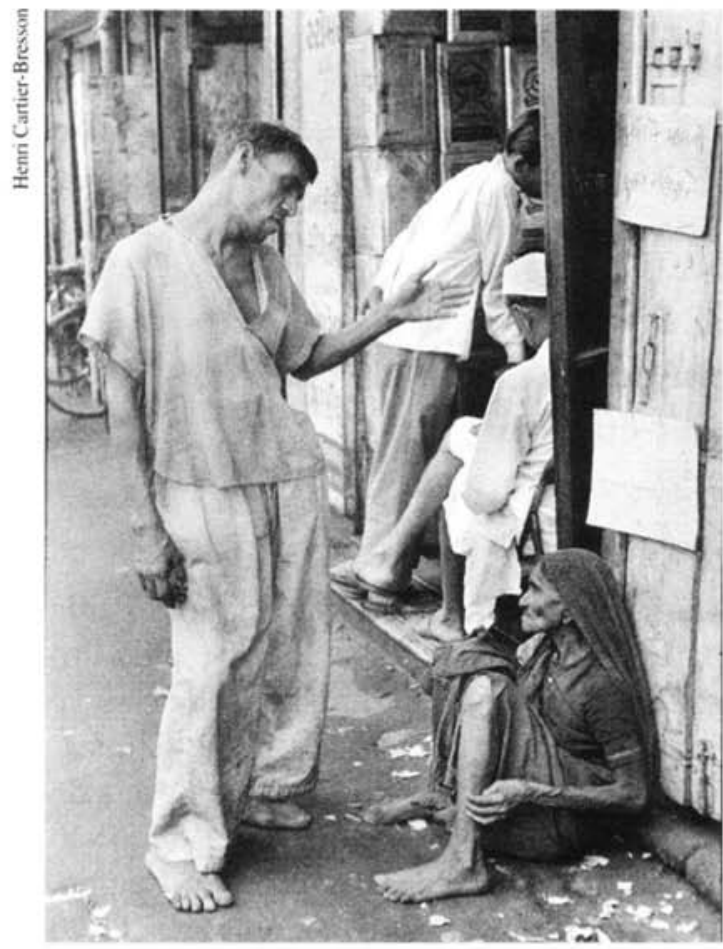

Extrato do cotidiano de Arabad, Índia, 1966.

reação da crítica. Mais provocativa ainda foi a publicação do romance $\mathbf{O}$ Almoço $\mathbf{N u}$, cujo erotismo foi considerado pornográfico. James Baldwin, como escritor negro, repudia o racismo e clama contra a corrida nuclear, Jaques Keroak do On the road, relata as experiências do grupo pelas estradas em busca do nada. Porém, considero

Resumo: O autor faz um breve retrospecto histórico sobre a presença da Imagem e suas transformaçōes na História da humanidade. Passa pelo mundo egípcio, pela arte grega, pela Roma Antiga, pela Idade Média, pelo Renascimento e chega até os meados deste século, mostrando como as imagens e as representaçōes artísticas estāo inseridas e são um produto do contexto socioeconômico-cultural de uma época.

Palavras-chave: História, imagem, História da Arte, Artes Plásticas
Alan Guinsburg, o poeta, que melhor traduz a angústia dessa geração rotulada de geração Beat. Seu primeiro poema, Uivo, de 1956, foi proibido por obscenidade. Nele pode-se perceber toda a visão trágica do mundo que caracteriza a postura dessa geração.

Mais expressiva ainda é a abertura de outro dos seus poemas chamado América: "América, eu lhe dei tudo e agora não sou nada./ América, dois dólares, vinte e sete centavos, 17 de janeiro de 1956./ América, não agüento mais a minha própria mente./ América, quando acabaremos com a guerra humana./ Vá se estrepar com a sua bomba atômica./ Não estou legal, não me encha o saco. /Não escreverei o meu poema enquanto não me sentir legal./ América, quando é que você será angelical?/ Quando você tirará sua roupa?(...)”

Considero este um dos poemas mais pungentes do mundo contemporâneo e que mostra bem a ruptura que se inicia na década de 50.

É a partir desta década que se pode considerar o século XX. É um novo universo, plurifacetado, pela via das Histórias em Quadrinhos, da Arte-Pop, do vídeo-arte, do grafismo, sem contar a televisão.

E esta é uma outra metamorfose que, agora, envolve o problema da imagem objeto, da imagem mercadoria.

Abstract: The author carries out a brief historical retrospect on the presence of the Image and on its transformation throughout the History of humanity. He goes through the Egyptian world, Greek art, ancient Rome, though the Middle Ages, Renascence, and reaches the middle of this century, showing how images and artistic representations are inserted and are a product of a period's socioeconomic and cultural context.

Keywords: History, image, History of Art, Plastic Arts 